\title{
Reproductive Endocrinal Regulation in Decapod Crustaceans: A review
}

\author{
Kumari Aprajita*, A.K. Pandey, R. Singh ${ }^{2}$ and U.K. Chauhan' ${ }^{1}$ \\ *Department of Fish Conservation Division, National Bureau of Fish Genetic Resources Lucknow - (UP) \\ 226002 \\ 1 Department of Environmental Biology and Biotechnology A.P.S University, Rewa (M.P) - 486003 \\ 2 Department of Fish Health and Management, National Bureau of Fish Genetic Resources \\ Lucknow - (UP) 226002
}

\begin{abstract}
Due to the growing requirement of high protein food from aquatic sources and to find a substitute for fisheries, prawn culture is the major restricted access in crustacean aquaculture industry. It is imperative to understand the physiological mechanisms involved in seed production of the candidate species. This review was carried out on studies of endocrine regulation of reproduction in giant fresh prawn Macro brachium rosenbergii. This type of work seems to be a practical substitute to eyestalk ablation to induce spawning. Since it is a commercially important crustacean, crustacean aquaculture industry and these hormonal manipulation like neurotransmitter and vertebrate type sex hormone indicted the possibility of introducing a new strategies for ovarian maturation in aquaculture.
\end{abstract}

Keywords: Crustacean, Neurotransmitters, Ovary, Vertebrate type steroids.

\section{Introduction}

Since past few years the culture of crustacean is import because it has a high demand due to the nutritional food sources in worldwide, but the major problem in the industry of crustacean aquaculture remains limited availability of good quality seed which is necessary for the culturing the crustaceans. For the seed availability the initiation of ovarian maturation and spawning in shrimp lobsters, and certain crab was carried out using the unilateral eye stalk ablation technique (Huberman, 2000; Tsukimura, 2001; Weilder et al., 2002; Diwan, 2005). But this technique is not very useful due to many problems like deterioration in spawn and spawner and larval quality and quantity over time and high mortality rate in brood stock. This also results in inferior quality of offspring produced (Benzie, 1998; Tsukimura and kememolo, 1991).
Alternative techniques to eye stalk ablation method, like temperature and or photoperiod manipulation, hormone and neurotransmitter injections have been investigated in different shrimp species (Sarojini et al., 1995; Vaca and Alfaro, 2000; Yano and Hoshino, 2006; Treerattrakool et al., 2008). It is necessary to discuss up to date research on role of hormone in gonadal maturation of crustaceans.

Regulation of hormone is one of the most common physiological processes in animals but some important process like molting are unique to the specific group of invertebrates. Many review papers have been published on the endocrinology of crustaceans. Earlier Quekenbush (1986), presented four types of compound which play an important role in the regulation of crustacean physiological process, these compounds are peptides, steroids, terpenoids and biogenic amines (Fig 1). 


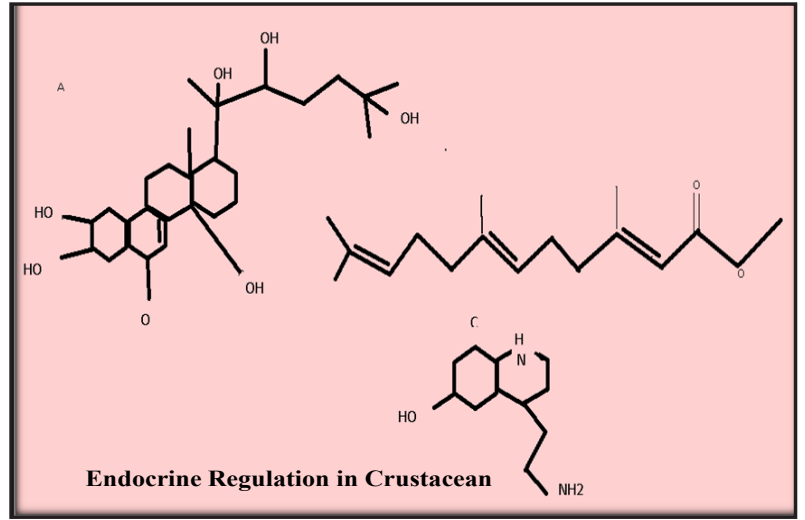

Fig. 1 Chemical structure of compounds play an important role in the regulation of crustacean physiology process A) Ecdysteroids-20 hydroxyecdysone, B) Terpenoids- Methyl fernosoate C)biogenic amines- Serotonin.

A further more recent review paper was mainly focused on growth and reproduction in crustacean endocrinology (Fingerman, 1997; Subramoniam, 2000). Physiologically these compounds are peptides, steroids, terpenoids and biogenic amines.

\section{Reproductive system in crustacean}

Reproduction is the process by which species are perpetuated; it is one of the primary activities to maintain the contest of any organism in the biosphere in natural ecosystem. Reproduction is regulated by several extrinsic and intrinsic factors and physiology of reproduction in invertebrates leading to the production of gametes is not yet clearly defined. In most of the crustaceans the male and female sexes are easy to identify due to the some special morphological characteristics like appendages on the abdomen and second chelate legs. The second chelate leg of male are larger and stronger than female, the male transfers the spermatophore through the penis to female sexual opening. Sperm in spermatophores fertilizes the eggs as they are laid. The fertilized eggs are attached to the female abdominal pleopods by long sticky threads secreted by the female (Fig. 2).

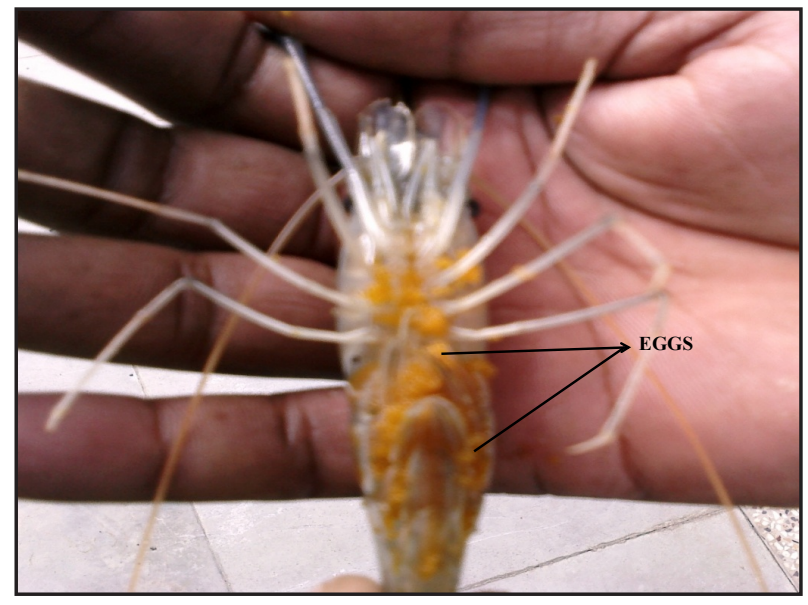

Fig. 2 Berried female $M$. rosenbergii lays their egg in abdomen through sticky thread.

In females, the paired ovaries are located dorsally to the stomach and hepatopancreas. They give rise a pair of oviducts which extend towards, and open into, the gonophores on the basal segment of the third pereopods.

\section{Male reproductive system}

The reproductive system of male crustacean consists of paired testes, vasdeferens, seminal vesicle and a genital aperture. Morphologically testes are white elongated structure (Fig 3). The testes are very much similar to structure of ovary and its appearance looks like an $\mathrm{H}$-like the gonophores opening located on the basis of the $5^{\text {th }}$ pair of periopods. The role of hormone in spermatogenesis process is yet not clearly defined. (Ganji and Chandra Nagaraju, 2011). In higher crustacean the androgenic gland is responsible for the male characteristics.

The internal reproductive structures of $M$. rosenbergii are located in the cephalothoraxes. In males, they consist primarily of pairs of testis which are fused and lie mid-dorsally in the cephalothoraxes, giving rise to the vas deferens. The paired vasdeferens are simple tubes that end in terminal ampulla, which contain the 


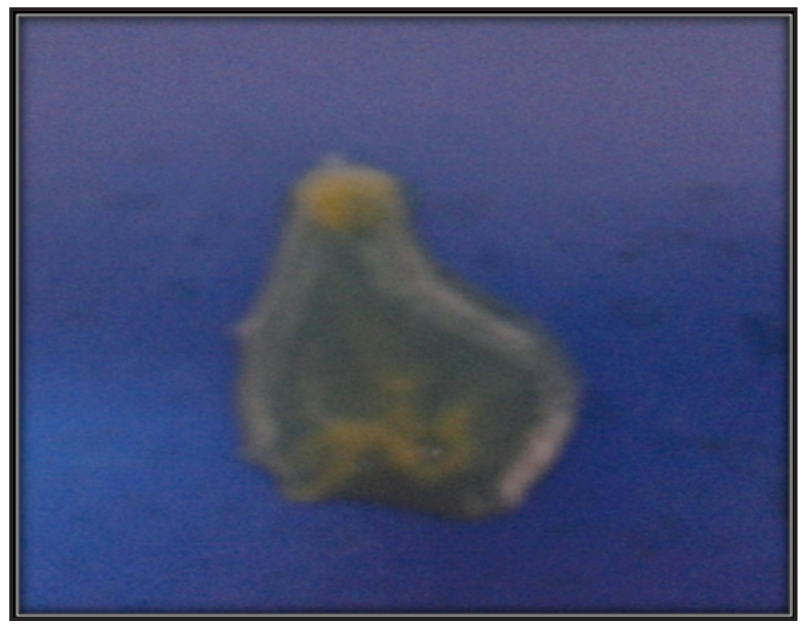

Fig. 3 Testis of male M. rosenbergii.

spermatophores and open at the gonophores on the coxae of fifth pereopods. During mating, the ampullae extrude the spermatophors, containing the sperm mass. Besides these structures, an androgenic gland is attached to the vas deferens. This Androgenic gland is the characteristic feature of males in crustaceans. Mostly it is linked with the sub terminal ejaculatory region of the sperm duct. This gland is located at last walking leg of Male prawn between the muscles of the coxapodite. The structure of Androgenic gland varies from one species to another species (Kleinholtz and Keller, 1979; Martin et al., 1990; Siddiqui et al., 1997). In the $M$. rosenbergii the androgenic gland is attached with the vas deferens (Awari and Dube, 1999). This gland secretes proteineceous substances (Taketomi, 1986; Awari and Dube, 1999). In the case of Macrobrachium rosenbergii surgical removal of the androgenic gland from juvenile M.rosenbergii at early developmental stage resulted in complete sex reversal, leading to the development of functional females capable of mating and producing progeny (Sagi et al., 1997a). Affect of androgenic gland on the expression of a vitellogenic-specific protein in the female and intersex Cherax quadricarinatus (Sagi et al., 1999), acquiescent the main role of the androgenic gland in change in sexual flexibility of the species.

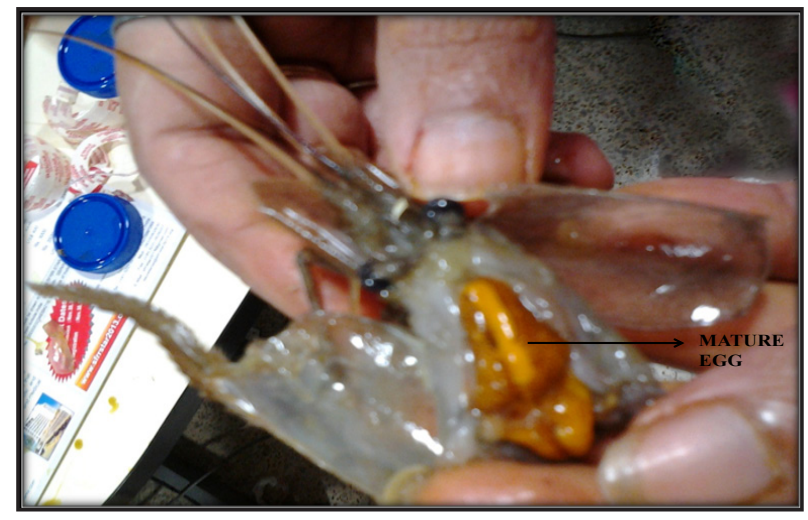

Fig. 4 Mature ovary of $M$. rosenbergii.

\section{Female reproductive system}

In the reproductive system of female crustacean a paired ovaries, oviduct, gonophore and a outer sperm reception area is present, the ovaries are clearly identified at the maturation stages which lie in the cephalothorax on the top of stomach and hepatopancears, oviduct consist of a ovary laterally just beside the position of heart, it opens in the abdomen through a gonophore. At the maturity stage cephalothoracic region is filled with the ovary. In the immature stage the ovarian color is transparent and when the process of vitellogenesis is started the color of ovary changes from the pale yellow orange but at the stages of spawning the color of ovary become dark brown. Due to proliferation the oocyte diameter increases due to the yolk deposition (Ganji and Nagaraju, 2011) (Fig 4.)

In crustaceans, extensive quantities of yolk accumulation are the basic requirement of embryonic and larval development within the developing oocytes during maturation. This type of changes are by the deposition of yolk material in the oocytes, which causes oocytes diameter to increase to rapidly and in each new maturation stages the color of oocytes changes due to the presence of specific components which is called carotenoid. In this case 
hemolymph vitellogenin concentration is a good indicator of the beginning of vitellogenesis during early maturation, rapidly increasing until maturation. Vitellogenesis in crustacean is a complex physiological phenomenon (Adiyodi and Adiyodi, 1970; Nagabhushanam et al., 1985; Subramoniam, 1999b). It is the process of formation of yolk protein,the main yolk protein are Vitellin (vn) and Vitellogenin(vg) which are linked with the lipid and carbohydrate. Mostly crustacean egg is full of yolk (Adiyodi and Adiyodi,1970; Nagabhushanam et al;1985). Giant fresh water prawn is a perennial breeders, and attains maturity at the length 14 c.m (Rajyalakshmi, 1961; Rao, 1991). Macrobrachium rosenbergii attains four maturity stages (Rao and Tripathi, 1993).

\section{Hormonal role in the case of reproduction in crustaceans}

Crustaceans employ two important exteteroceptive stimuli like temperature and photoperiod for precise tuning of their reproductive (production of gametes) as well as moulting (growth by shedding of old exoskeleton) activities to the most suitable environmental conditions. The shedding of exoskeleton is termed as ecdysis and the name of other phase is molt cycle. Shrimp undergoes several ecdyses before they attain juvenile size. With increase in size frequency of ecdysis is reduced, so control of growth is depend on the control of moulting. For long time, our knowledge regarding neuro-endocrine control of reproduction in the prawn is concerned with the regulation of ovarian maturation in females. In the case of decapods, yet it is well known that reproduction is primarily controlled by two antagonistic peptide hormones which emerge from different origin: i) gonad-inhibiting hormone $(\mathrm{GIH})$ is secreted from the X-organ-sinus gland (XO/SG) complex, located in the eyestalks (Quackenbush,1989) which inhibits ovarian development and ii) gonad-stimulating hormone (GSH) secreted from the brain and thoracic ganglia (Otsu,1963) stimulates the ovarian development though the chemical nature, mode and site of action of GIH are well known (Huberman, 2000), but exact work of GSH has been not yet clearly defined. Study shows that the stimulatory effects of brain and thoracic ganglia arises on ovarian maturation (Fingerman, 1997). Thus, it appears that, the coordination between these two hormones is crucial in the regulation of ovarian maturation. It has been reported that the synthesis and release of GIH and GSH from XO/SG complex and brain and thoracic ganglia, respectively are believed to be modulated by biogenic amines (Richardson et al., 1991 and Fingerman, 1997). Ecdysteroids like ecdysone, 20-hydroxyecdysone (20-oh-ecdysone) and 3-dehydroecdysone have been isolated from the $Y$-organ and ovary of prawns. It is a non-neural epithelial endocrine gland located in the maxillary segment of cephalothoracic region (Bliss, 1951; Chang, 1992; Isamal and New, 2001). $\mathrm{Y}$-organ is the source of the molting hormone and they play central role in molting but their functional significance in spermatogenesis in male and vitellogenesis in female decapods crustacean is not yet clearly defined (Cormier et al., 1992). Mandibular organ of crustacean is a non neural endocrine gland situated in the cephalothoracic region just above the first pair of pleopods (Laufer et al., 1987). Mandibular organ (MO) secretes terpenoids like methyl farnesoate (MF) and Farnesoic acid (FA) which are mainly corcenerned with molting and play a critical role in reproduction (act as gonadotropins) as suggested by (Laufer and Sagi, 1991; Laufer et al., 1993), reported that MF could be used as morphogens. This suggests the role of Methyl fernosoate in reproductive and morphogenesis of crustaceans though hexahydroxyfernesyl acetone. Farnesyl-acetone have identified secretions of the androgenic gland (AG). Recent studies characterized two proteinaceous hormones like Androgenic gland hormone I (AHI) and Androgenic gland hormone II (AHI) which play important role in musculanization of prawns. These observation 
suggest that modulation of reproduction in prawns are controled by a multi-hormonal system. In this factors of different chemical nature and origin play direct or indirect role in gonadal development, sexual differentiation and mating behavior.

\section{Role of neurotransmitter (biogenic amines) on gonadal maturation of crustacean}

Biogenic amines are mostly involved in the physiological activity in decapods (Fingerman, 1997). It plays dual work, first as neuroregulators and second as a neurohormones. They put their effects on target tissues (Fingerman and Nagabhushanam, 1992; Luschen et al., 1993; and Sneddon et al., 2000. Sainath et al., 2011). Neurohormones play most important role in the reproduction of the crustacean, and neurotransmitter involves in the formation and release of number of neurohormones (Richardson et al., 1991). There are two basic antagonistic neurohormones which regulate the gonadal maturation; gonad inhibiting hormone $(\mathrm{GIH})$, released from the $\mathrm{X}$-organ sinus gland in the eyestalk optic lobes of crustaceans inhibits the gonadal maturation and the gonad stimulating hormone (GSH), released from the brain and thoracic ganglia, which are involved in stimulating the gonadal maturation. Vitellogenesis-stimulating hormone (VSH) also called gonad-stimulating hormone, $(\mathrm{GSH})$ is released from the brain and thoracic ganglia (EastmanReks and Fingerman, 1984) and methylfarnesoate from the mandibular organ (Laufer et al., 1993). The synthesis and release of neurohormones in crustacean are believed to be regulated by biogenic amines (Richerdson et al., 1991). A neurotransmitter 5-Hydroxytryptamine (5-HT) also called serotonin present in the central nervous system of crustaceans (Butler and Fingerman, 1983; Laxmyr, 1984; Fingerman et al., 1994). It functions as a neurotransmitter which stimulates the release of the ovary (OV)-stimulating hormone in the fiddler crab Uca pugilator, red swamp crayfish Procambarus clarkia (Richardson et al., 1991;
Luschen et al., 1993) and other organisms. Neurotransmitter such as serotonin (5-HT) and dopamine (DA) are known to various effects on decapods crustaceans, including ovarian maturation, which is observed by histological and histochemical method as well as ELISA. In prior studies neurotransmitter $5-\mathrm{HT}$ is involved in the crustacean reproduction because its of stimulatory effects on gonadal development and maturation of male gonadal maturation in U. pugilator (Sarojini et al., 1995a) and female gonadal maturation in P.clarkii, Litopenaeus vannamei, and Penaeus monodon (Vaca and Alfaro, 2000; Wongprasert et al., 2006). Further, 5- HT induces ovarian maturation both in vitro and in vivo and the stimulatory effect of 5-HT on ovarian maturation is most probably mediated by triggering $\mathrm{GSH}$ which are released from the brain and thoracic ganglia (Vaca and Alfaro, 2000). The physiological role of 5-HT in the neuroregulation of shrimp remains to be clarified. The synthesis and release of these neurohormones in crustaceans are believed to be regulated by biogenic amines (Richardson et al., 1991), both 5-hydroxytryptamine (5-HT, serotonin) and DA. Dopamine is also present in the central nervous systems of crustaceans (Fingerman et al., 1994) and works as a neurotransmitters/neuromodulators (Luschen et al., 1993)., It work as a neurotransmitter and is responsible for the stimulation of both pigment concentrating hormone $(\mathrm{PCH})$ (Fingerman and Fingerman, 1977) and distal retinal pigment dark-adapting hormone (DRPDaH) (Kulkarni and Fingerman, 1986). In the fiddler crab, Uca pugilator it has also been demonstrated that dopamine also promotes the crustacean hyperglycemic hormone from the $X$ organ-sinus gland complex of Orconectes limosus and the shore crab, Carcinus maenas (Luschen et al.,1993). The tiger shrimp Penaeus monodon Kuo et al., 1995 and the freshwater giant prawn M. rosenbergii (Kuo and Yang, 1999). Dopamine works as an antagonist of 5-HT which stimulates the testicular maturation in the fiddler crab, U. pugilator (Sarojini et al., 1995a) and the red swamp crayfish, P. clarkia 
(Sarojini et al., 1995b) and ovarian maturation in $P$. clarkii. Many neurotransmitters have been shown to affect the release of these reproductive hormones like dopamine (DA) stimulates GIH in eyestalk (Fingerman, 1997) and inhibits $\mathrm{GSH}$ in thoracic ganglia. While serotonin (5-HT) stimulate GSH release (Fingerman, 1997). 5-HT also involves in the stimulation of other hormones, including crustacean hyperglycemic hormone $(\mathrm{CHH})$ (Keller and Beyer, 1968) red pigment dispersing hormone (RPDH) (Rao and Fingerman, 1970) molt inhibiting hormone (MIH) (Chang, 1985; Mattson and Spazaini, 1985) and black pigment dispersing hormone (BPDH). In addition, it was reported that female crayfish, Procambarus clarkii, given $5-\mathrm{HT}$ exhibited a significant increase in ovarian index and oocyte size (Sarojini et al., 1995). Similar results are reported from several crustacean species, with a substantial increase of vitellogenin content in the hemolymph during vitellogenesis (Lee, 1991). Vitellogenesis acts as a biomarker in female reproductive activities, which indicate that the vitellin accumulation gradually increased in oocytes during ovarian development (Quackenbush, 1989). In our study the effect of neurotransmitters on the ovarian development and vitellogenesis in the adult fresh water prawn $M$. rosenbergii was studied with the analysis of GSI and quantification of vitellogenin in hemolymph of both control and treated prawns. The 5-HT treated prawn showed observable histological changes resulting in shortening the period of the ovarian development as well as increase Gonado somatic index and oocyte diameter whereas dopamine had the opposite effect.

\section{Gonado Somatic Index (GSI)}

GSI is the main sign of ovarian development. The GSI was gradually increased during experimental period by the injection of serotonin. The GSI value in control is $2.9 \pm$ to 0.04 and $\mathrm{GSI}$ value increased to $3.88 \pm 0.88$ by the injection of serotonin. Whereas, GSI show no

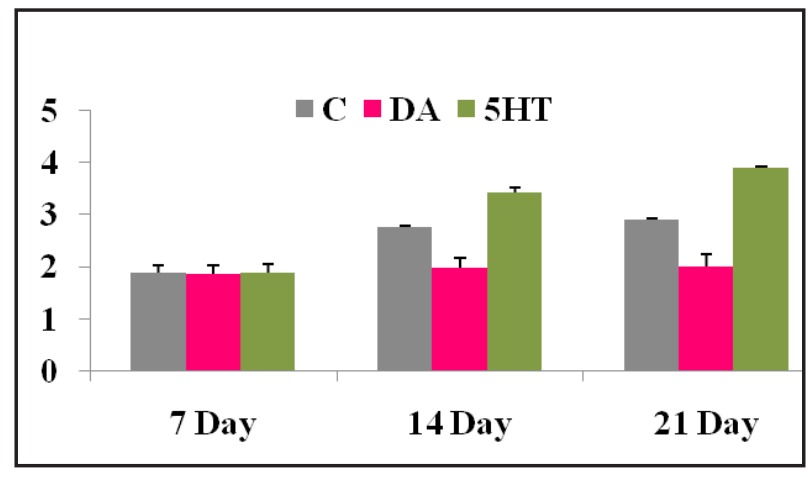

Fig. $5 \mathrm{GSI}$ of control and experimental $M$.rosenbergii treated with dopamine (DA) and serotonin (5- HT).

significant increase by the injection of Dopamine ( $2 \pm 0.03)$ in comparison to control and serotonin injected prawn. On the other hand, GSI values differed significantly by the injection of these neurotransmitter $(P<0.05)$, (Fig.5).

After the histological observations of the ovary, in the case of control the ova diameter was $31.1 \pm 0.23 \mu \mathrm{m}$ to $57.1 \pm 0.13 \mu \mathrm{m}$ and no significant changes were observed neither in gonado somatic index nor in the oocytes diameter in control in 21 days experimental period. Administration of DA did not result in any significant changes in gonado somatic index and in the oocytes diameter $(30.8 . \pm 0.23 \mu \mathrm{m}$ to $46.8 \pm 0.11 \mu \mathrm{m})$ in the comparison of control during the experimental duration. On the other hand, injection of serotonin significantly increases the gonad somatic index and oocytes diameter $(45.7 \pm 0.15 \mu \mathrm{m}$ to $247.4 \pm 0.15 \mu \mathrm{m}$. Fig. 6, 7\&8).

The histological observations of the ovary from DA injected prawn indicated that the ovaries were at immature stages, whereas the ovary of experimental prawn treated with serotonin was in vitellogenic stages which could be evidenced by the appearance of yolk globules in the oocytes of the fresh water prawn $M$. rosenbergii. Therefore, it has been suggested that these two biogenic amines play opposite roles in controlling ovarian development and oocyte maturation in prawn. 


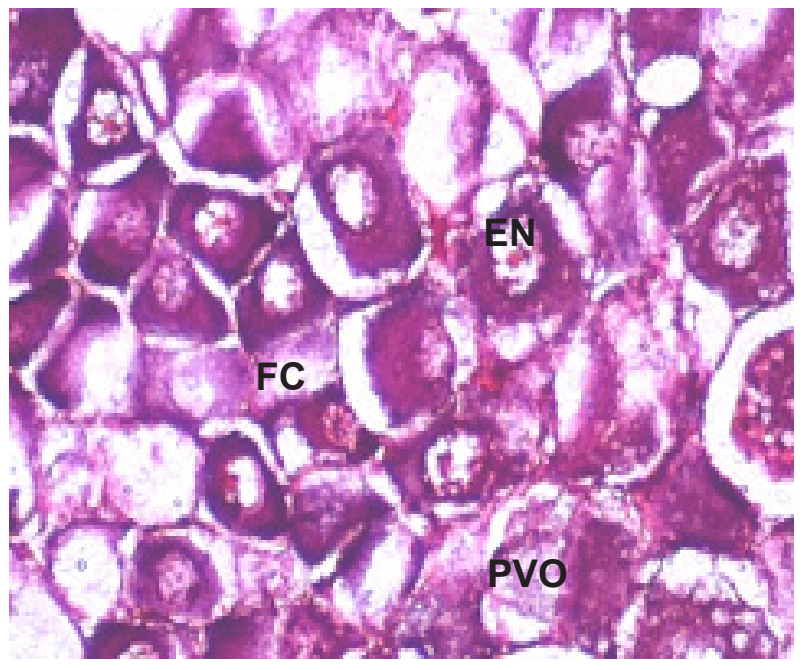

Fig. 6 Ovary of experimental control females M. rosenbergii (Neurotransmitter) showing oogonia and oocytes at previtellogenic oocytes (PVO), FC: follicular cells; H\&E × 200.

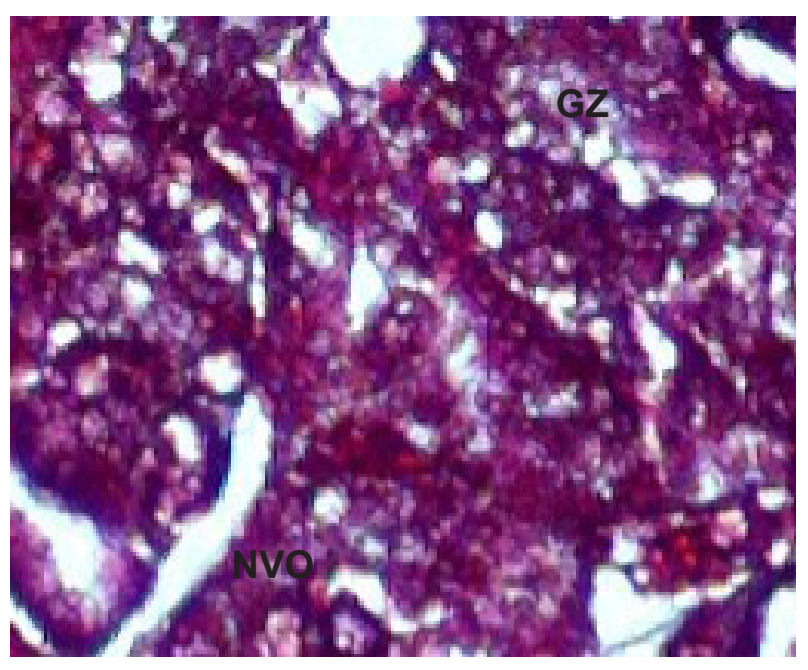

Fig. 7 Ovary of experimental dopamine treated females M. rosenbergii (Neurotransmitter) Showing; NVO: no vitellogenic oocytes, GZ: germinal zones; H\&E × 200 .

\section{The effect of vertebrate type sex hormone on the reproduction of crustaceans}

Several hormonal factors such as methyl farnesoate, a structural homologue of insect juvenile hormone, ecdysteroids as well as vertebrate steroids like 17ß-estradiol (E2) and

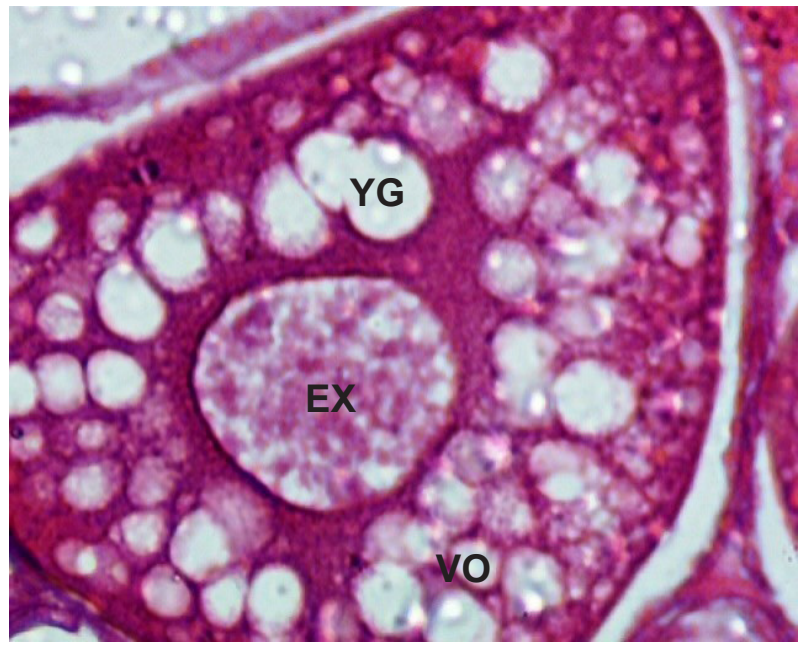

Fig. 8 Enlarged view of Ovary of experimental Serotonin (5-HT) treated females $M$. rosenbergii (Neurotransmitter) showing VO: Vitellogenic oocytes, YG: yolk globules; H\&E ×400.

progesterone $(P)$ have been implicated with encouragement of ovarian maturation in different crustacean species. Vertebrate-type sex hormones have been reported to be found in the hepatopancreas, ovary, and the hemolymph of crustaceans, their levels changes in correlation with the oocyte maturation cycle. It clarifies a positive correlation between vitellogenin (VTG) circulating levels and hemolymph levels of progesterone and 17- $\beta$ estradiol $\left(E_{2}\right)$ have been reported for crabs (Shih, 1997; Warrier et al., 2001; Zapata et al., 2003) and shrimps (E.coccia et al., 2010). Mostly the stimulatory effects of some vertebrate-type sex hormone such as $17 \beta$-estradiol and progesterone on ovarian growth on decapods have already been seen. In the crayfish $M$. rosenbergii, 17ß-estradiol behaved as a metabolic activator at the cellular level causing an increase in mitochondrial ATP-ase, cytosolic malate dehydrogenase, and glucose-6-phosphate dehydrogenase in the hepatopancreas (Ghosh and Ray, 1993a). In the case of Procambarus clarkii, 17 $\beta$-estradiol (E2) and 17-hydroxyprogesterone produced a significant increase in the gonadosomatic index, while in latter significant increase in oocyte diameter (Rodriguez et al., 2002b). In 
the case of crustaceans there is evidence that vitellogenin is synthesized in several tissues including the hepatopancreas and the ovary itself (Shafir et al., 1992; Khayat et al., 1994; Lee and Chang, 1999).In these organisms, secondary vitellogenesis is accompanied by the accumulation of yolk, composed of lipids, carbohydrates, and proteins (Adiyodi and Subramoniam, 1983) circulating in the hemolymph as VTG, a high-density lipoprotein (HDL) (Lee and Puppione, 1988,Abdu et al., 2000.In our study the effect of the sex steroids 17-ßestradiol and progesterone on giant freshwater prawn reproduction, is used as VTG marker. Female Macrobrachium rosenbergii which are injected with Progesterone and estradiol for ovarian development in comparison of control shows the appearance of many primary granule stage (PGS) oocytes contained in extensive accumulation of yolk granules dispersed throughout the cytoplasm.(Fig.9,10 and 11.)

The oocytes are in mature stage after the treatment of vertebrate type sex hormone in the comparison of control Vitellogenesis in crustacean is a complex physiological phenomenon, (Nagabhusnam et al., 1985; Subramoniam, 1999b), Majority of decapods crustacean have yolky eggs. Hence vitellogenesis is the process of yolk synthesis and deposition is a crucial event in the female gametogenesis. Vitellin and lipovitelline is a major protein that is formed in the ovary during the process (Adiyodi and Adiyodi, 1970; Nagabhusnam et al., 1985).

The aim of this study is to present the physiological effects of DA on ovarian development of the decapods $M$. rosenbergii, and to explore its mechanism of action. Further attempt will be made to record the effect of the vertebrate type sex hormones (Progesterone and 17-ßestradiol) on the ovarian maturation and egg quality of the crustacean. Several crustaceans have the ability to synthesize the vertebrate type sex hormone such as progesteron; 17-ßestradiol and testosterone have been reported from various non-reproductive as well as reproductive organs such as mandibular organs,

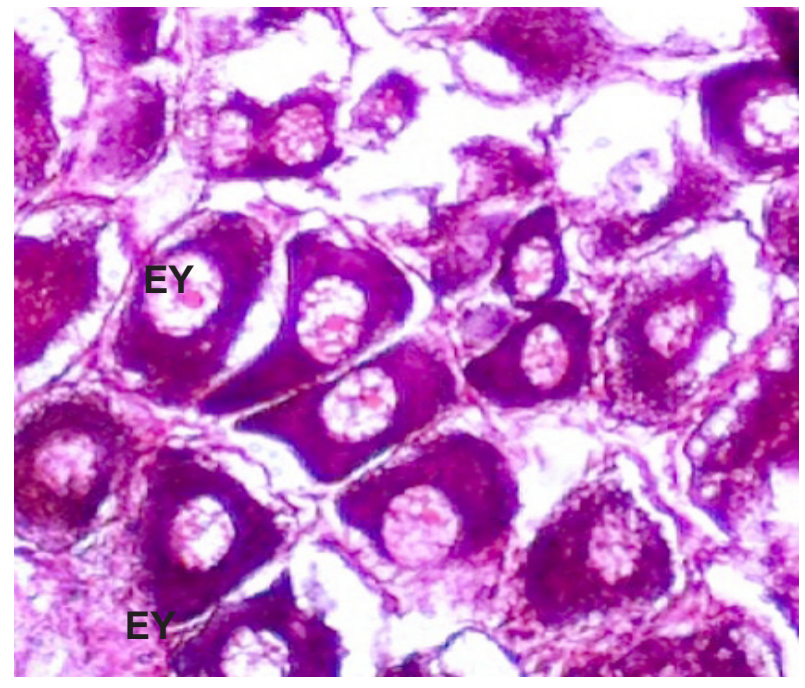

Fig. 9 Ovary of experimental control females $M$.rosenbergii vertebrate type sex hormone) showing pre Vitellogenic oocytes (PVO) H\&E $\times$ 200.

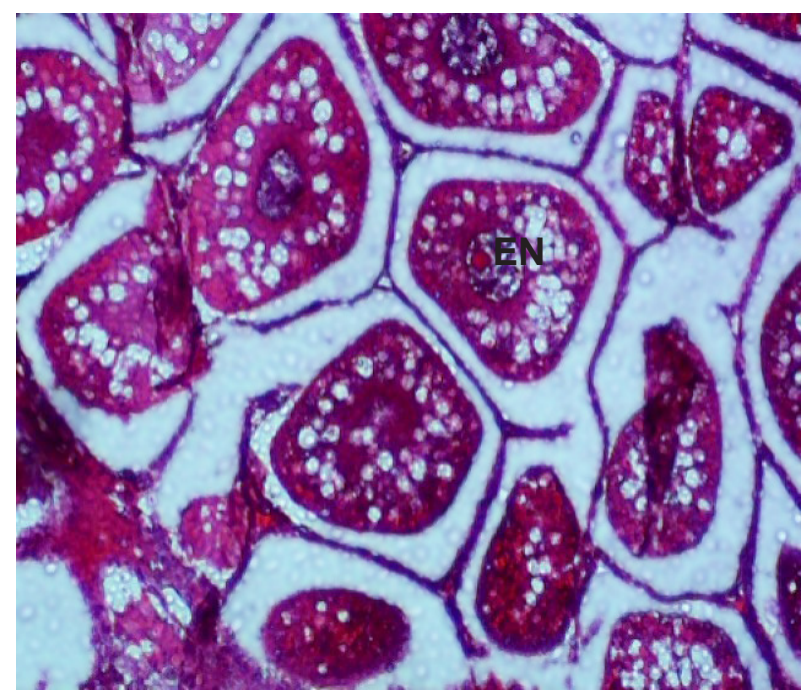

Fig. 10 Ovary of $M$. rosenbergii treated with progesterone showing the appearance of many primary granule stage (pyg) oocytes contained extensive accumulation of yolk granules dispersed throughout the cytoplasm. H\&E $\times 200$.

kidney, hepatopancreas, hemolymph, ovary and testis of the crustaceans (Yano, 1985; Subramoniam, 1999). This type of work also helps to understand the mechanism of hormonal role in gonadal maturation of the commercially important 


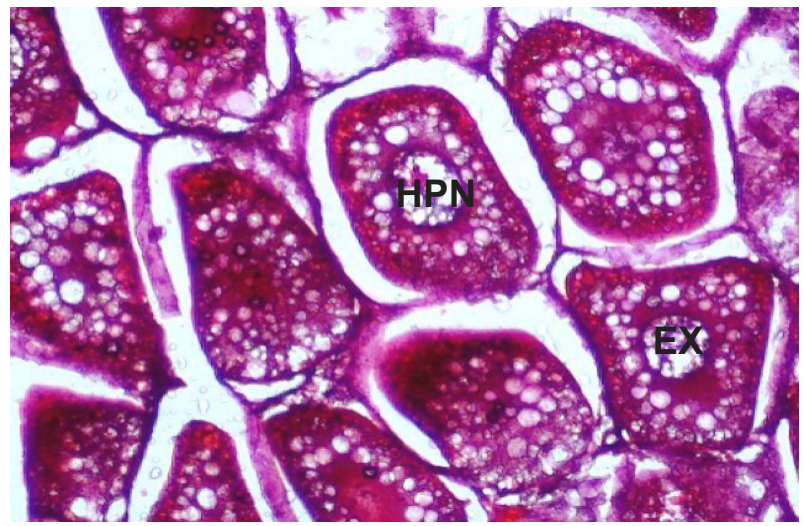

Fig. 11 Ovary of females $M$.rosenbergii treated with $17 \beta$-estradiol showing exogenous vitellogenic oocytes (EX) with perinuclear halo of nucleolar material H\&E × 200.

crustacean species and also provide possibility of these hormonal manipulations for the better quality of seed production.

\section{Acknowledgements}

The authors are grateful to the Director NBFGR Lucknow for giving opportunity and providing hatchery facility for successful completion of our experiment.

\section{References}

Abdu, U., Yehezkel, G., and Sagi, A. (2000). Oocyte development and polypeptide dynamics during ovarian maturation in the red-claw Crayfish Cherax quadricarinatus. Invertebr. Reprod. Dev., 37, 75-83.

Adiyodi, R. G., and Subramoniam, T. (1983), ArthropodaCrustacea. In K.G Adiyodi and R.G Adiyodi, eds. Reproductive Biology of Invertebrates, Oogenesis, Oviposition and Oosorption. John Wiley and Sons, Chichester, England. 1,443-495.

Adiyodi, R.G., and Adiyodi, K.G. (1970) Endocrine control of reproduction in decapods crustacean. Biol.Rev. 45, 121-165.

Awari, S. A., and Dube, K. (1999) Histological and histochemical study of androgenic gland of Macrobrachium rosenbergii.(de Man). J.Aqua. Trop., 14, 101-112.

Benzie, J.A.H. (1998). Penaeid genetics and biotechnology. Aquaculture., 164: 23-47.

Bliss, D.E. (1951). Metabolic effect of sinus gland eye stalk removal in the land crab, Gecarciaus lateralis, Anat.Rec., 111, 502-503.
Butler, T.A. and. Fingerman, M. (1983) Concentration of neurotransmitter in the central nervous system of Uca panacea and Callinectes sapidus. Amer. Zool., 23,954-958.

Chang, E.S. (1992). Endocrinology, Marine shrimp cultutre,Principle and Practices.Development in aquaculture and fisheries science. Elsevier Science Publisher B.V., 23, 53-93.

Chang,E.S.(1985).Hormonal control of molting in decapod crustacea. Amer. Zool., 25, 179-185.

Cormier, R., Fraser, J., Bailey, A.R., and Raymond, R.F. (1992). Hemolymph ecdysone concenteration as a function in the male snow crab, Chionoecetes opilio.Can. J.Fish. Aquat. Sci., 49, 1619-1623.

Diwan A.D. (2005). Current progress in shrimp endocrinology - a review. Ind J. Exp. Biol. 43, 209-223.

E.coccia Coccia E, De Lisa E, Di Cristo C, Di Cosmo A, Paolucci M, (2010) Effects of estradiol and progesterone on the reproduction of the freshwater crayfish Cherax albidus. Biol Bull. Feb; 218(1), 36-47.

Eastman- Reks, S.B., and Fingerman, M.(1984). Effects of Neuroendocrine tissue and cyclic AMP on ovarian growth in vivo and in vitro in the fiddler crab, Uca pugilatar. Comp.Biochem. Physiol., 79, 679-684.

Eastman, Reks, S.B., and Fingerman, M.(1985) In vitro synthesis of vitellin by the ovary of the fiddler crab, Uca pugilator. J. Exp. Zool., 233, 111-116.

Kumari and Pandey

Fingerman, M. (1997). Roles of neurotransmitters in regulating reproductive hormone release and gonadal maturation in decapod crustaceans. Invert. Reprod. Dev., 31, 47-54.

Fingerman, M. and Nagabhushanam, R.(1992).Control of the release of crustacean hormones by neuroregulators. Comp. Biochem. Physiol., 102,343-352.

Fingerman, M., and Fingerman, S. W. (1977) Antagonist action of DA and 5-hydroxytryptamine on color change in the fiddler crab, Uca pugilator. Comp. Biochem. Physiol., 58C,121-127.

Ganji, P and Chandra, Nagaraju. (2011) A Review on reproductive regulators in decapods crustacean the $J$ of Exp Biol, 214, 3-16

Ghosh, D., and Ray, A. K. (1993a). Subcellular action of estradiol-17 in a freshwater prawn, Macrobrachium rosenbergii. Gen. Comp. Endocrinol., 90, 274-281.

Huberman, A. (2000). Shrimp endocrinology. A review, Aquaculture. 191-208. 
Ismael, D., New, M. B., (2000). Biology. In M.B. New \& W.C. Valenti, eds. Freshwater prawn culture, the farming of Macrobrachium rosenbergii, pp. 18-40. Oxford, England, Blackwell Science.

Keller, R., and Beyer, J. (1968) Zur hyperglyka"mischen Wirkung von Serotonin und Augenstielextrakt beimFlußkrebs Orconectes limosus. Z. Vgl. Physiol., 59,78-85.

Khayat, M., Lubzens, E., Tietz, A and Funkenstein, B. (1994b) Are vitellin and vitellogenin coded by one gene in marine shrimp Penaeus semisulcatus.J.Mol. Endo.,12,251-254.

Kleinholtz, L.H., and Keller, R.(1979). Endocrine regulation in crustacean, hormones and evolution, (Ed,E.J.W.Barrington).Academic Press., New York. 161-213.

Kulkarni, G.K., and Fingerman, M. (1986), Distal retinal pigment of the fiddler crab, Uca pugilator: evidences for stimulation of release of light adapting and dark adapting hormones by neurotransmitter. Comp. Biochem .Physiol. 84C, 219-224.

Kuo, C. M., and Yang.(1999). Hyperglycemic responses to cold shock in the freshwater prawn Macrobrachium rosenbergii. J.Comp.Physiol., 169(B), 49-54.

Kuo, C.M., Hsu, C.R., Lin, C.Y., (1995). Hyperglycaemic effects of DA in tiger shrimp, Penaeus monodon. Aquaculture 135, 161-172.

Laufer, H., Ahl, J.S.B. Sagi, A. (1993) The role of juvenile hormones in crustacean reproduction. Am. Zool., 33,365-374.

Laufer, H., and Sagi, A. (1991). Juvenile hormone like compound and Reproduction in male and female crustaceans: with implication for Aquaculture. Bull. Inst.Zool.Acad. Sinica., 16, 541-551.

Laufer, H., et al.,(1987). Identification of a juvenile hormone-like compound in a crustacean. Science 235,202-205.

Laxmyr, L. (1984) Biogenic amines and DOPA in the central nervous system of decapod crustacean. Comp. Biochem. Phys. C 77,139-143.

Lee, F. Y., and C. F. Chang. (1999). Hepatopancreas is the likely organ ofvitellogenin synthesis in the freshwater prawn, Macrobrachium rosenbergii. J. Exp. Zool. 284,798-806.

Lee, R.F. (1991). Lipoproteins from the hemolymph and ovaries of marine invertebrates. In: Advances in comparative and environmental physiology, R. Gilles (Ed.).Springer Verlag, Heidelberg, Germany., 7,187-207.
Lee, R.F., and Puppione, D.L. (1988). Lipoprotein I and II from the hemolymph of the blue crab Callinectes sapidus:Lipoprotein II associated with vitellogenesis. J. Exp. Zool., 218, 278-289.

Luschen, W., Wilig, A., and Jaros, P.P. (1993) The role of biogenic amines in the control of blood glucose level in the decapod crustacean Carcinus maenas L. Comp. Biochem. Physiol. 105, 291-296.

Martin, G., Juchault, P., Sorokine, O. Van., and Dorsselear, A. (1990) Purification and charecterization of androgenic hormone from the terrestrial isopod, Armadillidium vulgari Latr. (Crustacea, Oniscidea).Gen. Comp. Endocrinol ., 80, 349-354.

Mattson, M.P., and Spazaini E.(1985).5-hydroxytryptamine mediates release of molt inhibiting hormone activity from isolated crab eyestalk ganglia. Biol. Bull., 36, 347-358.

Nagabhushnam, R.,Reddy, T.S.N andSarojini,R.(1985).Biochemical variation in hepatopancreas and ovary during vitellogenic cycle of fresh water prawn Caridinia weberi.J.Adv.Zool., 6,81-86.

Otsu, T. (1963). Bihormonal control of sexual cycle in the freshwater crab, Potoman dehaani. Embryologia. $8,1-20$

Quackenbush, L.S. (1986) Crustacean Endocrinology.A review. Can. J. Fish. Aquat. Sci., 43,2271-2282.

Quackenbush, L.S. (1989) Vitellogenesis in the shrimp, Penaeus vannamei: in vitro studies of the isolated hepatopancreas and ovary. Comp. Biochem. Phys. B 94,253-261.

Rajyalakshmi,T.(1961). Observations on the biology and fishery of Metapenaeus brevicornis (M.Edw.)in the Hooghly estuarine system. Ind J. Fish., 8(2),303-402.

Rao, K. J., and Tripathi, S. D.(1993) A manual on the giant freshwater prawn hatchery. Manual series2. Central Institute of Freshwater Aquaculture, Bhubaneshwar.

Rao, K.J. (1991). Reproductive biology of the Giant fresh water prawn Macrobrachium rosenbergii (deMan) from lake kolleru (A.P) Ind J. Ani. Sci., 61(7), 780-787.

Rao, K.R., and Fingerman, M. (1970). Action of biogenic amines on chromatophores: II. Analysis of the response of erythrophores in fiddler crab, Uca pugilator, to indolealkyl amines and eyestalk hormone. Comp. Gen. Pharmacol., 11,117-126. 
Richardson, H.G., Deecaraman. M., and Fingerman, M. (1991). The effect of biogenic amines on ovarian development in fiddler crab, Uca Pugilator. Comp. Biochem. Physiol., 99,53-56.

Sagi, A. Snir, E., and Khalaila, I. (1997) Sexual differentiation in decapods crustaceans:role of androgenic gland. Invert. Reprod. Develop., 31,55-61.

Sagi, A., Khalalia, I., Abdu, U., Shoukrun, R., and Weil, S. (1999) A newly established ELISA showing the effect of the androgenic gland on secondaryvitellogenic specific protein in the hemolymph of the Crayfish, Cherax quadricarinatus. Gen. Comp. Endocrinol. 115,37-45.

Sagi, A., Shoukrun. R., Levy, T., Barki, A., Hulata, G., and Karplus, I. (1997). Reproduction and molt in previously spawned and first time spawning red claw crayfish Cherax quadricarinatus females following eyestalk ablation during the winter reproductive arrest period. Aquaculture., 156,101-111.

Sainath, S. B., Sreenivasula, P. and Reddy. (2011) Effect of selected biogenic amines on reproduction in the fresh water edible crab, Oziotelphusa senex senex. Aquaculture. 313,144-148.

Sarojini, R., Nagabhushanam, R., Fingerman, M. (1995a) In vivo inhibition by dopamine of 5-hydroxytryptamine-stimulated ovarian maturation in the red swamp crayfish, Procamburus clarkii. Experientia. 51,156-158.

Sarojini, R., Nagabhushanam, R., Fingerman, M., (1995b). Evidence for opioid involvement in the regulation ofovarian maturation of the fiddler crab, Uca pugilator. Comp. Biochem. Physiol. 111A, 279-282.

Shafir S, M Ovadia, M Tom. (1992) In vivo incorporation of labeled methionine into protein, vitellogenin, and vitellin in females of the penaeid shrimp Penaeus semisulcatus de Haan. Biol. Bull. 183,242-247.

Shih, J. T.(1997). Sex steroid-like substance in the ovaries, hepatopancrea and body fluid of female Mictyris brevidactylus. Zool. Stud., 36, 136-145.

Siddiqui, A, Q. Al, Hafedh. Y. S. Al, Harabi. A.H., and Ali, S. A.(1997). Effects of stocking density and monosex culture of fresh water prawn Macrobrachium rosenbergii on growth and production in concrete tanks in Saudi Arabia. J.World Aqua. Soc., 28(1),106-112.

Sneddon, L. U., Taylor, A.C., Huntingford, F. A. Watson., D.G. (2000). Agonistic behavior and biogenic amines in shore crabs Carcinus maenas. J. Exp. Biol., 203,537-545.

Subramoniam, T.(1999b) Endocrine regulation of egg production in economically important crustaceans. Current Sci., 76, 350-368.
Subramoniam,T.(2000). Crustacean ecdysteroids in reproduction and embrogenesis.Comp. Biochem. Physiol.,125,135-156.

Takayanagi, H., Yamamoto, Y and Takeda, N. (1986). An ovary stimulating factor in the shrimp, Paratya compressa. J. Exp. Zool. 240,203-209.

Taketomi, Y. (1986). Ultra structure of androgenic gland of the Crayfish, Procambarus clarkia. Cell. Biol. Int. Rep.,10,131-136

Treerattrakool, S., Panyim, S., Chan, S.M., Withyachumnarnkul, B., and Udomkit, A. (2008). Molecular characterization of gonad-inhibiting hormone of Penaeus monodon and elucidation of its inhibitory role in vitellogenin expression by RNA interference. FEBS J., 275,970-980.

Tsukimura, B. (2001). Crustacean vitellogenesis: its role in oocyte development. Amer. Zool., 41,465-476.

Tsukimura,B.,Kamemoto,F.I.(1991).In vitro stimulation of oocytes by presumptive mandibular organ secretions in the shrimp,Penaeus vanaamei. Aquaculture 92,59-66.

Vaca, A and Alfaro, A, J. (2000). Ovarian maturation and spawning in the white shrimp, Penaeus vannamei, by serotonin injection. Aquaculture., 182,373-385.

Warrier, S. R., Tirumalai, R. and Subramoniam, T.,(2001), Occurrence of vertebrate steroids, estradiol-17b and progesterone in the reproducing females of the mud crab Scylla serrata. Comp. Biochem. Physiol., 130, 283-294.

Wilder, M.N., Subramonaian, T., Aida, K. (2002). Yolk proteins of crustacean in , Adiyodi, K.G and Adiyodi R.G (Eds). Reproductive biology of invertebrates. Science Publishers Inc, Enfield. USA.131-174.

Yano, I. (1985). Induced ovarian maturation and spawning in greyback shrimp. Metapenaeus ensis, by progesterone, Aquaculture., 47, 223-229.

Yano, I., Hoshino, R. (2006). Effects of $17 \beta$-estradiol on the vitellogenin synthesis and oocyte development in the ovary of kuruma prawn, Marsupenaeus japonicus. Aquaculture, 144,18-23.

Zapata, V., Lopez Greco, L.S., Medesani, D., Rodriguez, E.M. (2003): Ovarian growth in the crab, Chasmagnathus granulata induced by hormones and neuroregulators throughout the year. In vivo and in vitro studies. Aquaculture, 224,1-4. 